\title{
Morphology of the vertebral artery in Asian population
}

\author{
Maryna Alfaouri-Kornieieva', Azmy M. Al-Hadidi ${ }^{2}$ \\ ${ }^{1}$ Department of Anatomy, Faculty of Medicine, Tabuk University, Tabuk, KSA, ${ }^{2}$ Department of Diagnostic Radiology and Nuclear Medicine, \\ Faculty of Medicine, University of Jordan, Amman, Jordan
}

Background: Recent clinical trials have shown a rising trend of stroke in Asian population. Approximately $20 \%$ strokes of total occur at the vertebrobasilar basin that supplies the occipital lobes of the brain, the cerebellum, and the brainstem. The anatomical features and variability of the third segment of the vertebral artery (VA) in Asians are analyzed in this study. Methods: A prospective cohort study of 68 consecutive Asian patients underwent MRA examination for head and neck in the Department of Radiology of Hospital of University of Jordan from 1.10.2011 to 30.04.2012. The 116 VA were analyzed on the obtained angiograms. Results: The third segment (V3) of the VA was studied according to its conventional division into vertical, horizontal, and oblique parts. The mean outer diameter of the V3 varied up $3.18 \pm 0.73$ to $4.28 \pm 1.08 \mathrm{~mm}$. The parameter prevailed on the left in $91 \%$ cases and was greater in males, than in females. The distal loop of the VA projected downward in 26 cases on the right $(78 \%)$ and in 28 cases on the left $(74 \%)$. The tortuosity of loop-formations of V3 was evaluated subject to angles between their ascending and descending bends. Conclusion: In comparison with other ethnic groups, the V3 of the VA in Asians has lesser outer diameter, especially along its oblique part; the zero-distance between the occipital bone and horizontal segment of VA occurs more often (up to $26 \%$ ); the Lang's III type of V3 variability is the most common in Asians.

Key words: Vertebral artery, variability, Asian population

\section{INTRODUCTION}

Stroke has become one of the most important health problems worldwide. ${ }^{1}$ Especially it is truth for Asian population, where upward bias of acute cerebrovascular pathology is registered during last 10 years. ${ }^{2}$ According to Ather $\mathrm{T}$ et al., the leading causes of stroke in Asians are small-vessel disease, intracranial atheroocclusive stenosis, and spontaneous intracerebral hemorrhage, while in Western studies the cardioembolic and atherosclerotic occlusive diseases are emphasized. These clinical features of stroke in Asians can be due to certain genetic specificity of the cerebral vascular bed in this population.

The most vulnerable source of cerebral blood supply is the vertebral artery (VA) in possession of complex course and relations with cervical vertebrae. Acute dissection as well as chronic obstruction of the VA leads to the basilar type of stroke that makes $20 \%$ of total. ${ }^{1,3}$ The VA is a branch of the subclavian artery. It ascends toward the transverse foramen of C6 vertebrae (V1), and then passes vertically through the transverse foramina of C6 to C2 (V2). After leaving the transverse foramen of $\mathrm{C} 2$, it runs over the axis and atlas (V3) and enters the cranial cavity (V4). Eventually the right and left vertebral arteries join to form the basilar artery. The course of the VA along its length is very tortuous. ${ }^{4}$ That is especially true for the V3 segment, where the artery changes its course three times from vertical, to horizontal, and then to oblique direction. ${ }^{5}$ The vertical segment extends from the transverse foramen of the axis until outlet of the transverse foramen of the atlas. It loops laterally forming the proximal loop of the V3, while the horizontal part makes backward extension forming the dorsal loop of the V3. ${ }^{6}$ The oblique segment is the ascending part of the V3 that stretches between the posterior arch of the atlas and inner edge of the foramen magnum, where it continues to the V4 segment. 
Knowledge of variability and inherent morphological features of the vascular system in main human's populations has been a useful attainment in the practice of particular specialist. This study has been undertaken to evaluate the morphological features of the third segment of the VA in males and females of the Asian population.

\section{MATERIALS AND METHODS}

Sixty eight patients of the Department of Radiology of Hospital of University of Jordan not known to have vascular pathology in the vertebrobasilar system were included to our prospective study. The age of study population ranged from 35 to 79 years (mean age 58 years), $45 \%$ were females and $55 \%$ were males. The patients underwent routine magnetic resonance (MR) examination of head and neck during period from 1.10.2011 to 30.04.2012 under the direct supervision of one of the authors in accordance with the ethical standards of the Hospital's Ethics committee.

The MR angiography was performed with the patients' heads in neutral position. After the contrast medium was injected into the forearm vein, the Flash 3D sequence scan from head to aortic arch were carried on automatically with slice thickness $1.4 \mathrm{~mm}$ and TR $3.2 \mathrm{~ms}$, TE $1.2 \mathrm{~ms}$ and Fov $34 \mathrm{~cm}$. On obtained MRA images, the course and tortuosity of the third segment of the VA (64 arteries) were studied and analyzed according to its conventional division into three sections: vertical, horizontal, and oblique (Figure 1). The length and outer diameter of each segment of the V3 were measured on the anteroposterior view angiograms. In order to evaluate the tortuosity of the artery, we measured the angles between bends of the proximal and distal loops (a1, a2), and the angle between the horizontal and oblique segments of the VA (a3) (Figure 2a). Also, the distance between the upper edge

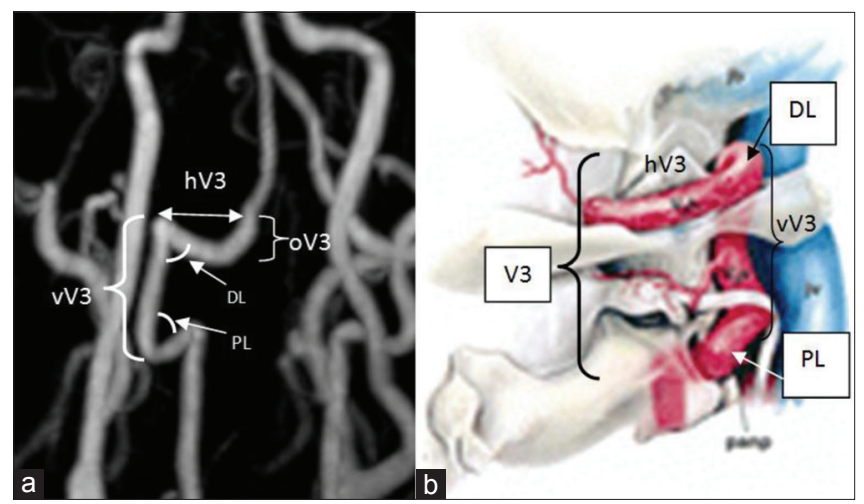

Figure 1: (a) MR angiography of head and neck: anteroposterior view, V3 of the right vertebral artery is marked; (b) Schema of the right vertebral artery. $v$ V3 - vertical segment of the vertebral artery; hV3 - horizontal segment of vertebral artery; oV3 - oblique segment of the vertebral artery; PL - proximal loop of V3; $\mathrm{DL}$ - distal loop of $\mathrm{V} 3$ of the horizontal part of the vessel and the imaginary transverse line, drawn through its origin and ending was evaluated (Figure $2 \mathrm{~b}$ ).

\section{Statistical analysis}

The means and standard deviations of resultant data were calculated for each studied group individually. Student paired t-tests and ANOVA tests were used to detect significant differences in the obtained values of $\mathrm{V} 3$ in the compared groups $(\mathrm{P}=<0.05)$.

\section{RESULTS}

The mean outer diameter of the VA gradually decreased from $3.9 \pm 1.08 \mathrm{~mm}$ in the vertical extent to $3.4 \pm 0.72 \mathrm{~mm}$ in the oblique one (Table 1). Mainly, the parameter was greater in the male on the left, however, right-dominating type was revealed in $9 \%$ of cases.

The length of the V3 along the vertical, the horizontal, and the oblique parts was equal to $23.22 \pm 2.7 \mathrm{~mm}$, $17.2 \pm 2.85 \mathrm{~mm}$, and $12.31 \pm 1.8 \mathrm{~mm}$ respectively. The segments were longer in males than in females (Table 1).

The proximal loop of the $\mathrm{V} 3$ is the first lateral extension of the V3 in the coronal plane. The mean angle between the ascending and descending bends of the proximal loop (a1) was equal to $73.8 \pm 1.8$ degree with the slight prevalence on the left (Table 2).

The distal loop of the VA projected downward in 26 cases on the right $(78 \%)$ and in 28 cases on the left $(74 \%)$. The mean distance from the imaginary horizontal line drawn

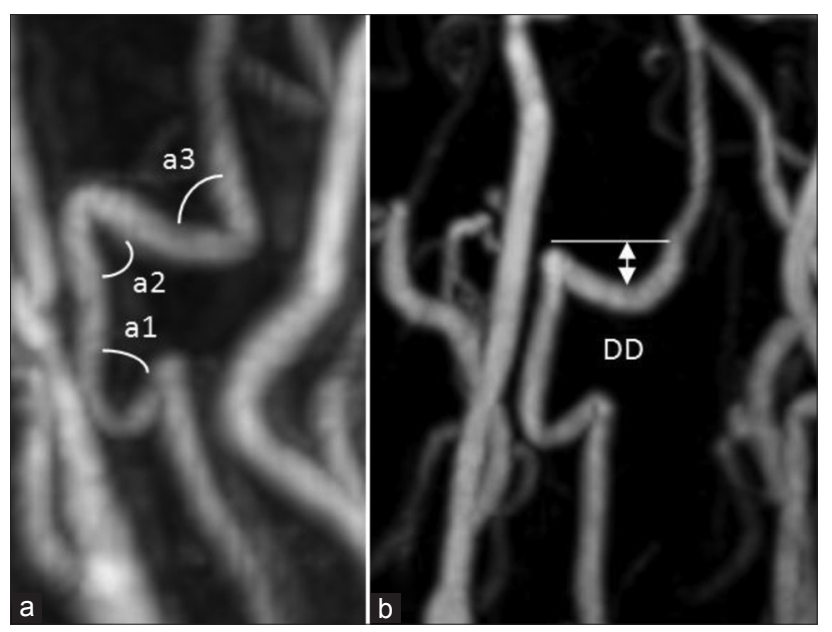

Figure 2: MR angiography of head and neck. (a) Anteroposterior view: a1 - angle between bends of the proximal loop; a2 - angle between bends of the distal loop; a3 - angle between the hV3 and oV3; (b) Anteroposterior view: DD - distance between the upper edge of $\mathrm{hV} 3$ and imaginary transverse line; $c$ ) lateral view: PL-DL - distance between apices of the proximal and distal loops of V3 


\begin{tabular}{|c|c|c|c|c|c|c|c|}
\hline & & \multicolumn{2}{|c|}{ vV3 } & \multicolumn{2}{|c|}{ hV3 } & \multicolumn{2}{|c|}{ oV3 } \\
\hline & & Right & Left & Right & Left & Right & Left \\
\hline \multirow[t]{2}{*}{ Males } & Width & $3.73 \pm 0.92^{* * *}$ & $4.28 \pm 1.08^{* *}$ & $3.73 \pm 0.95^{\star}$ & $4.01 \pm 1.01^{*}$ & $3.46 \pm 0.87^{* * *}$ & $3.68 \pm 1.02^{* * *}$ \\
\hline & Length & $22.98 \pm 2.52^{*}$ & $24.63 \pm 2.23 \mathrm{NS}$ & $16.86 \pm 1.86 \mathrm{NS}$ & $18.09 \pm 2.41^{*}$ & $12.47 \pm 2.37^{\star}$ & $12.92 \pm 2.05 \mathrm{NS}$ \\
\hline \multirow[t]{2}{*}{ Females } & Width & $3.75 \pm 1.05^{\star * *}$ & $3.98 \pm 1.01^{*}$ & $3.77 \pm 0.92^{*}$ & $3.91 \pm 1.07^{* \star *}$ & $3.18 \pm 0.73^{* *}$ & $3.38 \pm 0.81^{*}$ \\
\hline & Length & $22.55 \pm 2.80^{*}$ & $22.74 \pm 2.91^{*}$ & $16.57 \pm 2.37^{\star *}$ & $17.45 \pm 2.43 \mathrm{NS}$ & $11.78 \pm 1.18^{* *}$ & $11.71 \pm 1.03^{*}$ \\
\hline
\end{tabular}

Significance levels: $* * * p<0.001 ; * * p<0.01 ; * P<0.5 ;$ NS: No statistical significance. $v V_{3}$ : Vertical segment of the vertebral artery, hV 3 : Horizontal segment of the vertebral artery, $\mathrm{OV}_{3}$ : Oblique segment of the vertebral artery

\begin{tabular}{|c|c|c|c|c|}
\hline & a1, D & a2, D & a3, D & $\mathrm{DD}, \mathrm{mm}$ \\
\hline \multicolumn{5}{|l|}{ Males } \\
\hline Right & $72.13 \pm 1.48$ ** & $75.4 \pm 1.06^{* *}$ & $105 \pm 1.2^{\star \star *}$ & $6.14 \pm 1.93^{\star *}$ \\
\hline Left & $75.66 \pm 1.57^{*}$ & $68.8 \pm 1.23^{*}$ & $101.47 \pm 1.31^{* *}$ & $5.95 \pm 1.59^{\text {** }}$ \\
\hline \multicolumn{5}{|l|}{ Females } \\
\hline Right & $72.62 \pm 1.53^{* * *}$ & $75.18 \pm 1.38^{\star *}$ & $104.43 \pm 3.16^{* * *}$ & $4.7 \pm 2.01^{* *}$ \\
\hline Left & $74.87 \pm 2.08^{\star *}$ & $69.12 \pm 1.3^{*}$ & $\begin{array}{l}98.62 \pm 1.49 \\
\text { NS }\end{array}$ & $5.49 \pm 1.89^{*}$ \\
\hline
\end{tabular}

Significance levels: ***p<0.001; ** $\mathrm{P}<0.01 ; * \mathrm{P}<0.5 ;$ NS: No statistical significance. a1- the angle between bends of the proximal loop of the $V_{3}$; a2: The angle between bends of the distal loop of the $V_{3} ;$ a3: The angle between the $h V_{3}$ and o $V_{3}$ segments of VA; DD: The distance between the upper edge of the $h_{3}$ and imaginary transverse line, drawn through its origin and ending

through origin and ending of the horizontal segment of the VA to the most superior edge of the distal loop was $6.04 \pm 1.63 \mathrm{~mm}$ in males and $5.09 \pm 1.93 \mathrm{~mm}$ in females. The angle between ascending and descending bends of the distal loop (a2) was 75.29 \pm 1.21 degree on the right and $68.96 \pm 1.25$ degree on the left. The blunt angle between the horizontal and oblique parts (a3) was bigger on the right than on the left (Table 2).

\section{DISCUSSION}

The V3 segment of the VA is the most vulnerable source of blood supply for organs of the posterior cranial fossa. ${ }^{4}$ Due to significant dilation during the head rotation the V3 became a favorable area of sudden dissections. ${ }^{7,8}$ This segment of the VA possesses number of bends and loops those increase the resistance of blood flow generating target places for arteriosclerosis, thrombosis, and wall calcification. ${ }^{6,9}$ Chronic ischemia in the dependent on vertebral artery areas clinically leads to imbalance, disruption of motor coordination, dizziness, disturbance of vision. Dissection of the VA as well as its iatrogenic damage often results in the basilar stroke with high unfavorable outcome. ${ }^{3,4}$ The knowledge of variability and anatomical features of the VA in different human populations gives the main clues for understanding and prognosis of the pathological processes in the studied area.

The gender and side differences of the width and length of the V3 segment of the VA were repeated in literature. ${ }^{5,10}$ However, the comparative analysis of the values of the V3 part of the artery in Asian population with the results in the other ethnic groups had been never done before. The aim of this work is to clarify the anatomical features of the V3 segment of the VA in Asians to compare them with the reported research made at the Western, Southern, and Northern foundations.

\section{Comparison of dimensions of the VA in different ethnic groups}

Comparative analysis of the dimensions of the suboccipital part of the VA in Asians with analogues parameters obtained from published research made in other ethnic groups shows certain morphological distinctions. The mean diameters of the vertical and horizontal segments in Asians are lesser than in the other ethnic groups (Table 3). The best match it has with the results of Mitchell J, who carried out the meticulous analysis of 188 vessels obtained from cadavers of South African adults. ${ }^{11}$ However, she counted the outer diameter of the V3 as a mean value of the width of the horizontal and oblique segments.

The length of the vertical part of the VA in our research is greater than that reported by Turliuk DV et al. (Russia) and Muralimohan S et al. (India), but it concedes to results of Lang J et al. (USA). ${ }^{10,12,13}$ But the length of the horizontal segment of the V3 in the Asians is two times shorter than in Indian ethnic group (Table 3).

Although, the study of different populations above shows steady dominance of the left-side supply to the basilar system, in the present study the right-dominant type of the VA was found in $9 \%$ of Asians. On the basis of detailed analysis of 188 vessels, Mitchell J (South Africa) revealed no significant difference between the males and females, nor between the left and right sides. In addition, author revealed increasing of the outer and inner diameters of the vessel with age. ${ }^{11}$

The outer diameter of the oblique segment in Asians was significantly lesser in comparison with findings of Arthur J 


\begin{tabular}{|c|c|c|c|c|c|c|}
\hline $\begin{array}{l}\text { Authors (studied } \\
\text { ethnic group) }\end{array}$ & $\begin{array}{l}\text { Turliuk D } \\
\text { (Russians) }\end{array}$ & $\begin{array}{c}\text { Arthur J } \\
\text { (Americans) }\end{array}$ & $\begin{array}{c}\text { Lang J } \\
\text { (Americans) }\end{array}$ & $\begin{array}{l}\text { Muralimohan S } \\
\quad \text { (Indians) }\end{array}$ & $\begin{array}{l}\text { Mitchell J } \\
\text { (Africans) }\end{array}$ & $\begin{array}{l}\text { Precent research } \\
\text { (nsAsia) }\end{array}$ \\
\hline \multicolumn{6}{|l|}{ vV3 } & 116 \\
\hline $\mathrm{D}$ & $4.6 \pm 1.2$ & - & $4.14(2.5-5.0)$ & 4.8 & - & $3.9 \pm 1.08$ \\
\hline $\mathrm{L}$ & $16.4 \pm 1.7$ & - & $38.91(29-56)$ & $15.04 \pm 1.53$ & - & $23.22 \pm 2.7$ \\
\hline \multicolumn{7}{|l|}{ hV3 } \\
\hline D & $4.4 \pm 1.1$ & $4.85 \pm 1.45$ & $4.2(2.5-6)$ & 4.8 & **3.75 20.72 & $3.8 \pm 0.51$ \\
\hline $\mathrm{L}$ & - & - & - & $35.57 \pm 2.44$ & - & $17.2 \pm 2.85$ \\
\hline \multicolumn{7}{|l|}{ oV3 } \\
\hline $\mathrm{D}$ & $4.4 \pm 1.1$ & $4.5 \pm 0.3$ & $4.23(2-6)$ & - & ${ }^{* *} 3.75 \pm 0.72$ & $3.4 \pm 0.72$ \\
\hline Left/right difference & Yes & Yes & $99 \%$ * & Yes & No & $91 \%$ \\
\hline Gender difference & - & Yes & Yes & - & No & Yes \\
\hline
\end{tabular}

* The value concerned only to $\mathrm{VV}_{3}$ segment, there was zero-correlation for $\mathrm{hV} \mathrm{V}_{3}$ and o $\mathrm{V}_{3}$ parts. ** The value is mean for $\mathrm{hV} / 3$ and oV 3 . $\mathrm{D}: \mathrm{Outer}$ diameter; $\mathrm{L}$ : Length

et al. (USA), Lang J et al (USA), Turliuk D et al. (Russia) (Table 3). ${ }^{5,10,12}$ We found that the width of the oblique part was gradually tapering toward the foramen magnum. At the point of dural penetration the lumen of the vessel became the narrowest, especially in females $(3.2 \pm 0.68 \mathrm{~mm})$ (Figure 3). According to Peltier J et al., the narrowing of the VA at the level of the dural crossing is due to entering of perpendicular collagen fibers of the dura into the vascular wall. ${ }^{14}$

The distance between upper edge of the horizontal segment and the lower surface of the occipital bone estimated by Arthur J et al. (USA) in his research is equal with the interval of downward deviation (DD) in our study. ${ }^{5}$ According to his findings, the mean distance from the occipital bone to the upper edge of the artery was $6.0 \pm 2.8 \mathrm{~mm}$ on the right and $5.6 \pm 2.3 \mathrm{~mm}$ on the left, with zero-space in $6.9 \%$. The data we have received in the present research do not show significant difference with those above (Table 2). But it must be emphasized, that in Asians the zero-DD distance was observed in $22 \%$ on the right and $26 \%$ on the left that is significantly higher than in the Western research. The distance between the horizontal part of the artery and the occipital bone is a decisive factor during execution of the paramedian incisions in order to expose the foramen magnum or the lower cerebellopontine angle. ${ }^{15}$

The correlation of the dimensions of the $\mathrm{V} 3$ with gender is proved in our research; it also was marked by Lang J et al. (USA) and Arthur J. et al. (USA) in their works. ${ }^{5,10}$ But authors investigated South Africans and Indians cadavers reported no difference concern to the measurements of the V3 in the male and female groups. ${ }^{11,12}$

Estimation of the loop formations of the V 3 in Asians The excess length of the artery is the main mechanism to prevent its compression between the atlas and the occipital bone in excessive head movements, and accordingly, to

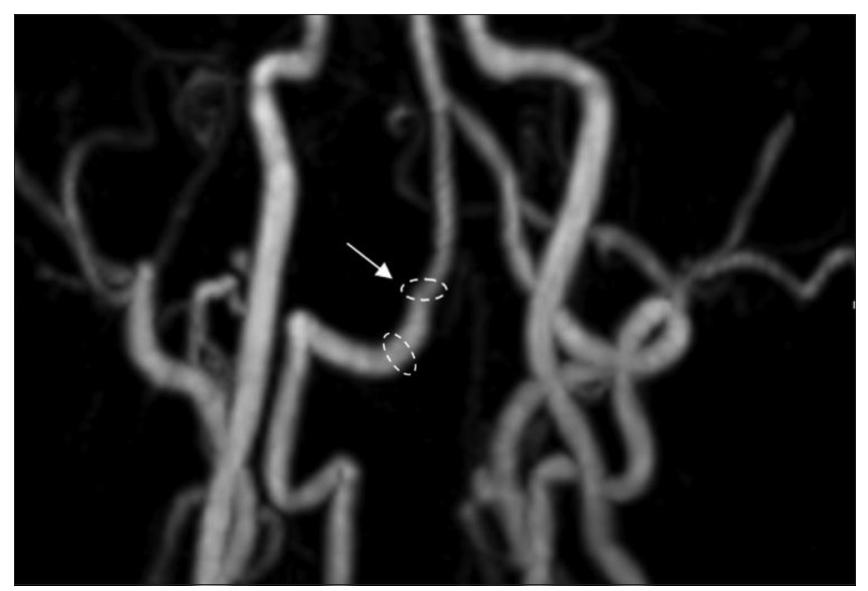

Figure 3: MR angiography of head and neck: anteroposterior view. The oblique segment of vertebral artery (oV3) deviates up from its horizontal segment under blunt angle. Origin of the oV3 and point it penetrates the dura matter (arrow) are marked on the angiogram above

avert the onset of the vertebrobasilar insufficiency. ${ }^{8}$ On the other hand, the proximal and distal loops of the V3 may be inadvertently damaged during surgery on the craniovertebral junction due to their great variance. ${ }^{15}$

Lang $J$ et al. proposed to classify the variability of the loop-formations of V3 into 4 types, according to their shape and direction. The type 1 was described him as a "textbook like" and was marked by the authors as the most prevalent type (64.6\%) in Western population. The type II was characterized with a distal loop sideward more or less caudally, and was found him in nearly 14\%; the type III was revealed in $10.8 \%$ and showed clear loops in the dorsal direction; the type IV the V3 was strained between the transverse foramen of the axis and the foramen magnum that occurred in 10.8\% cases. According to our findings, the most common type of the $\mathrm{V} 3$ variability in Asian population was type III with evident dorsal loop formations $(68 \%)$, while the $\mathrm{I}^{\text {st }}$ type was revealed only in $24 \%$ of cases. 
According to Shaoyin D et al. (2009-2010), the loops extension becomes more evident with age providing acute angles along the V3 lumen; it leads to resistance of blood flow, and generates target places for arteriosclerosis, thrombosis, and wall calcification prepossessing to the risk of onset of the vertebrobasilar insufficiency. ${ }^{16-18}$ In the present study, the minimal angles between the ascending and descending bends of the proximal and distal loops of the V3 were found in males; the first had the smallest value on the right, while the second was minimal on the left (Table 2). So, we consider that the Asian patients of this studied group are predisposed to formation of the chronic occlusive diseases at the V3 segment of the VA. The evaluated angle between the horizontal and oblique parts was obligatory obtuse in all patients therefore this extent is not predisposed to any danger. Unfortunately, we cannot compare these data with similar results in other ethnic groups, because analogues investigations of the loop formations of the V3 were not found in the literature.

The anatomical characteristics of the V3 of the VA in Asian population have certain differences in comparison with other ethnic groups, thus. The knowledge and understanding of the specificity of the main blood sources are important for specialists providing basis for careful manipulations and competent prognosis of pathological processes in the supplied areas.

\section{ACKNOWLEDGMENT}

The authors wish to express their sincere appreciation to Mr. Mohamed Zaal Ramouni, supervisor of CT and MRI unit of the Department of Diagnostic Radiology and Nuclear Medicine, Jordan University Hospital, Amman, Jordan, for his technical artistic work.

\section{REFERENCES}

1. Ingall T. Stroke-incidence, mortality, morbidity and risk. J Insur Med 2004;36 (2):143-152.

2. Ather T and Ayeesha KK. Stroke in Asians. Pak J Neurol Sci 2007;2 (1):14-17.

3. Hyung L, Kim JS, Chung EJ, Yi HA, Chung IS, Lee SR, et al. Infarction in the Territory of Anterior Inferior Cerebellar Artery: Spectrum of Audiovestibular Loss. Stroke 2009;40:3745-3751.
4. Dodevski A and Tosovska-Lazarova D. Anatomical Features and Clinical Importance of the Vertebral Artery. Macedonian Journal of Medical Sciences. 2012;5 (3):328-335.

5. Arthur JU, Quiroga M, Russo A, Vittorio MR, Graziano F, Velasquez $A$ et al. Normal anatomical variations of the V3 segment of the vertebral artery: surgical implications. J Neurosurg Spine 2010;13:451-460.

6. Cacciola F, Phalke $U$ and Goel A. Vertebral artery in relationship to C1-C2 vertebrae: An anatomical study. Neurol India 2004;52:178-184.

7. Sheth TN, Winslow JL and Mikulis DJ. Rotational changes in the morphology of the vertebral artery at a common site of artery dissection. Canadian Association of Radiologists Journal 2001;52 (4):236-241.

8. William B, Taylor III, Clayton L, Vandergrif F, Michael J, Opatowsky et al. Bowhunter's syndrome diagnosed with provocative digital subtraction cerebral angiography. Proc (Bayl Univ Med Cent) 2012;25 (1):26-27.

9. Ravensbergen J, Ravensbergen JW, Krijger JK, Hillen B and Hoogstraten HW. Localizing role of hemodynamics in atherosclerosis in several human vertebrobasilar junction geometries. Arterioscler Thromb Vasc Biol 1998;18 (5):708-716.

10. Lang $\mathrm{J}$ and Kessler B. About the suboccipital part of the vertebral artery and the neighboring bone-joint and nerve relationships. Skull Base 1991;1:64-72.

11. Mitchell J. Differences between left and right suboccipital and intracranial vertebral artery dimensions: an influence on blood flow to the hindbrain? Physiotherapy Research International 2004;9 (2):85-95.

12. Turliuk DV, lanushko VA and loskevich NN. Topographical and anatomical characteristics of the vertebral artery in the third segment. Angiol Sosud Khir 2009;15 (3):37-42.

13. Muralimohan S, Pande A, Vasudevan MC and Ramamurthi R. Suboccipital segment of the vertebral artery: A cadaveric study. Neurology India 2009;57 (4):447-452.

14. Peltier J, Toussaint P, Deramond H, Gondry C, Bruniau A, Gontier MF et al. The dural crossing of the vertebral artery. Surg Radiol Anat 2003;25: 305-331.

15. Peng CW, Chou BT, Bendo JA, and Spivak JM. Vertebral artery injury in cervical spine surgery: anatomical considerations, management, and preventive measures. The Spine Journal 2009;9:70-76.

16. Shaoyin D, Hongwei $H$, Shaomao $L$ and Liaobin $C$. Three-dimensional CT study on the anatomy of vertebral artery at atlantoaxial and intracranial segment. Surg Radiol Anat 2010;32:39-44.

17. Shaoyin D, Shaomao LÜ, Feng YE, Qingchi L and Liaobin C. Three-dimensional CT angiography study on the relations between the vertebral artery and atlantoaxial joint. Chinese Medical Journal 2009;122 (8):917-920.

18. Shaoyin D, Shaomao L, Feng $Y$ and Qingchi L. Imaging anatomy and variation of vertebral artery and bone structure at craniocervical junction. Eur Spine J 2009;18:1102-1108.

Authors Contribution:

MAK - Measurements of vertebral artery with using MR angiograms of head and neck, performing the statistical analysis, revising the resultant data, paper-preparation; AMA - Selection of patients for routing MR-examinations and interpretation of obtained MR images and angiogram.

Source of Support: Nil, Conflict of Interest: None declared. 